\title{
GPS water level measurements for Indonesia's Tsunami Early Warning System
}

\author{
T. Schöne ${ }^{1}$, W. Pandoe ${ }^{2}$, I. Mudita ${ }^{2}$, S. Roemer ${ }^{1,{ }^{*}}$, J. Illigner ${ }^{1}$, C. Zech ${ }^{1}$, and R. Galas ${ }^{3}$ \\ ${ }^{1}$ Deutsches GeoForschungsZentrum GFZ, Potsdam, Germany \\ ${ }^{2}$ Badan Pengkajian Dan Penerapan Teknologi (BPPT), Jakarta, Indonesia \\ ${ }^{3}$ Institut für Geodäsie und Geoinformationstechnik, TU Berlin, Berlin, Germany \\ *now at: Norwegian Mapping Authority, Norwegian Hydrographic Service, Stavanger, Norway
}

Received: 13 August 2010 - Revised: 24 January 2011 - Accepted: 31 January 2011 - Published: 9 March 2011

\begin{abstract}
On Boxing Day 2004, a severe tsunami was generated by a strong earthquake in Northern Sumatra causing a large number of casualties. At this time, neither an offshore buoy network was in place to measure tsunami waves, nor a system to disseminate tsunami warnings to local governmental entities. Since then, buoys have been developed by Indonesia and Germany, complemented by NOAA's Deep-ocean Assessment and Reporting of Tsunamis (DART) buoys, and have been moored offshore Sumatra and Java. The suite of sensors for offshore tsunami detection in Indonesia has been advanced by adding GPS technology for water level measurements.

The usage of GPS buoys in tsunami warning systems is a relatively new approach. The concept of the German Indonesian Tsunami Early Warning System (GITEWS) (Rudloff et al., 2009) combines GPS technology and ocean bottom pressure (OBP) measurements. Especially for nearfield installations where the seismic noise may deteriorate the OBP data, GPS-derived sea level heights provide additional information.

The GPS buoy technology is precise enough to detect medium to large tsunamis of amplitudes larger than $10 \mathrm{~cm}$. The analysis presented here suggests that for about $68 \%$ of the time, tsunamis larger than $5 \mathrm{~cm}$ may be detectable.
\end{abstract}

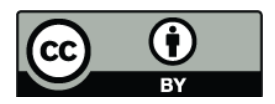

Correspondence to: $\mathrm{T}$. Schöne (tschoene@gfz-potsdam.de)

\section{Introduction}

Since the early 1990s, GPS technology has gained increasing interest in the scientific community.

A milestone has been the establishment of the International GPS Service in 1994 (Dow et al., 2009), enabling highly precise geodetic applications. However, the use of GPS in offshore applications has been limited by various factors, mainly maintenance costs, the bandwidth for data transfer and the accuracy and reliability of kinematic GPS processing over large distances.

In 1990, Hein et al. successfully introduced GPS technology on a buoy for calibrating the ERS-1 radar altimeter. Later, several other designs and applications were tested for GPS water level measurements (e.g., Born et al., 1994; Watson et al., 2008). Between 1999 and 2003 the International Association of Geodesy (IAG) implemented the special study group SSG 2.194 (IAG, $1999^{1}$ ) to internationally coordinate the geodetic efforts to advance this technique. In recent years, GPS buoys have become an integral part of the calibration and validation for radar altimeters (e.g., Watson et al., 2004; Bonnefond et al., 2009).

The first attempts to use GPS buoys for tsunami detection were made in Japan (e.g., Teruyuki et al., 2000; Toshihiko et al., 2006). In 2010, this technology became part of Japans Nationwide Ocean Wave information system for Ports and Harbors (NOWPHAS) (Teruyuki et al., 2010).

In 2003 Schöne et al. developed an offshore GPS buoy for multi-mission radar altimeter calibration in the North Sea. After the deadly tsunami in Banda Aceh (Indonesia)

\footnotetext{
${ }^{1}$ http://adsc.gfz-potsdam.de/altimetry/SSG_buoys/
} 


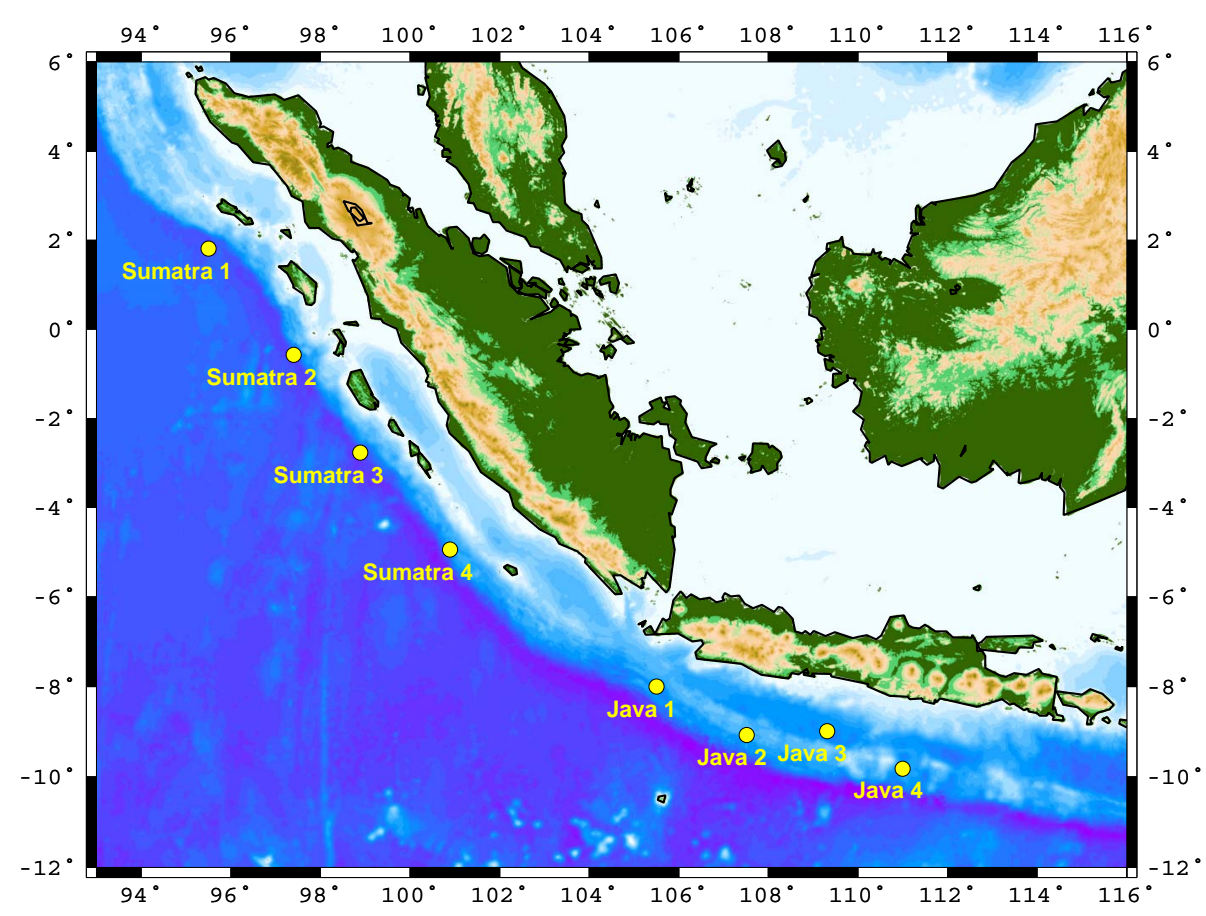

Fig. 1. GITEWS GPS buoy network in Indonesia supporting InaTEWS. The station network is complemented by InaTEWS buoys of BPPT. The configuration was designed in a way that a possible tsunami wave can be detected within five minutes after the earthquake source time.

in 2004, the design of this implementation was further advanced to add this novel technique to the Indonesian Tsunami Early Warning System (InaTEWS). Besides using GPS technology, the buoys serve as relay stations for different underwater acoustic units, e.g., the Pressure based Acoustically Coupled Tsunami detector (PACT) or the Ocean Bottom Unit (OBU) (Boebel et al., 2010). Within the scope of the GITEWS project (www.gitews.de, Rudloff et al., 2009), several GPS tsunami buoys have been deployed in Indonesia to complement the Indonesian InaTEWS buoy network (Fig. 1).

\section{Concept and design of the GITEWS GPS buoys}

Based on the concept and experience of the GPS buoy for radar altimetry calibration (Schöne et al., 2003), two prototype buoys were developed, delivered and installed in the first GITEWS test phase (March-November 2005). After this test phase a re-design of the buoy was made to better meet the needs of the tsunami warning system in Indonesia. The re-designed buoys are more robust due to an optimized material selection and larger diameter. In addition, the buoys support the underwater acoustic communication units better.

\subsection{Technical realisation}

The GITEWS tsunami buoys have to fulfill different requirements concerning the GPS component as well as for the OBU and PACT sensors (Boebel et al., 2010). Therefore, the design has to be a compromise between instrumentation, deployment depth, the environment in the deployment area, and the requirements arising from handling and maintaining the buoys in Indonesia. The buoy (Fig. 2a and b) meets these conditions, but its shape has mainly been optimized for stable sea behaviour (minimal and smooth tilting). Based on the numerical modelling (Dirk Berger, Altefähr/Germany) of key parameters (e.g., eigenfrequency, maximum tilt), a final technical design was developed. These key parameters were confirmed later-on by in-situ testing.

The diameter of the main body is $2.2 \mathrm{~m}$ with a height of $\sim 2 \mathrm{~m}$ to provide buoyancy for the payload and to withstand forces due to the mooring even under rough sea state conditions. A short basement construction enables easy transportation and handling in an upright position. Inside the basement construction, the mooring is connected to the main body of the buoy with a near to center-of-gravity connection. The main body also hosts a watertight compartment for the batteries and instrumentation. The total height of the buoy construction including the tower is $\sim 6 \mathrm{~m}$. Most parts of the buoy are made of steel except a few parts are made of aluminum to reduce their weight. The latter is necessary to simplify handling and maintaining the buoy and to damp the buoy's dynamics by adding counterweights. While at a shipyard, the tower can be detached to allow easy access to the batteries and the science compartment.

The antennas for data communication as well as the GPS antenna are mounted on the top ring of the tower. Furthermore, the tower provides sufficient space for the solar 


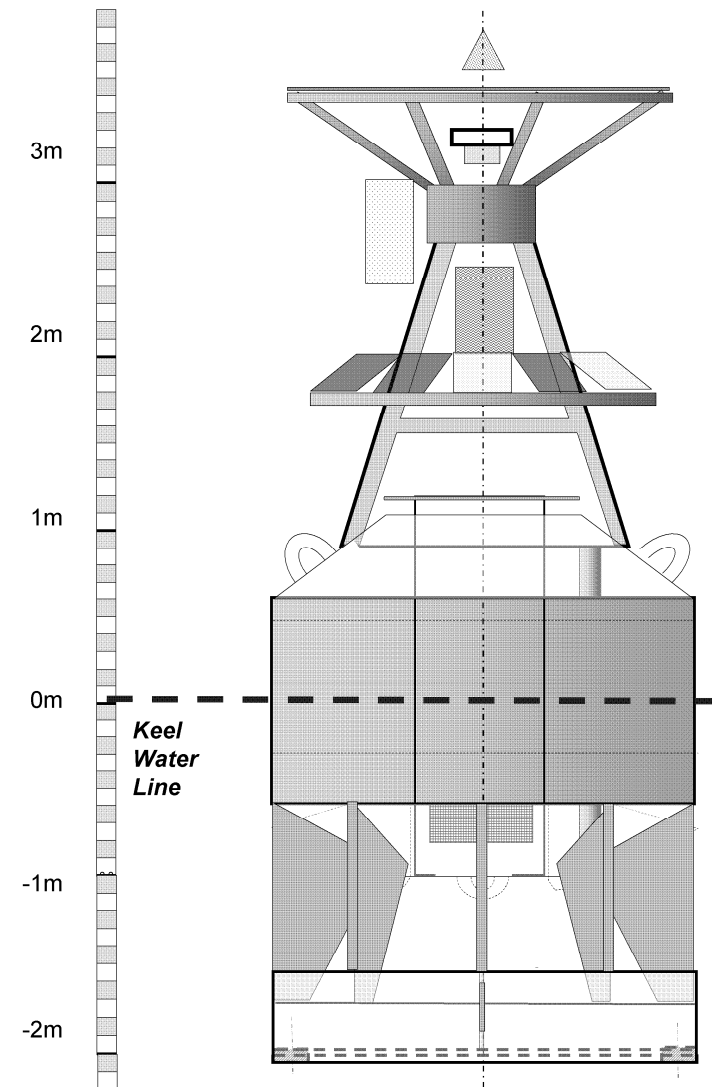

Fig. 2a. Schematic layout of the GITEWS buoy. The construction was designed and calculated by Dirk Berger, Altefähr/Germany.

panels which have been designed and optimized in shape (SOLARA AG, http://www.centrosolar.de/) to fit them to the buoy's dimensions. The solar panels are installed with an in-average optimal orientation for equatorial solar conditions and provide sufficient power to ensure a $24 \mathrm{~h}$ continuous operation throughout the year. In addition, meteorological sensors are mounted inside the tower construction. For security reasons, the tower houses LED lighting and a passive radar reflector to improve the visibility for the nautical traffic.

The mooring was designed by Nautilus $\mathrm{GmbH}$ (Bremen) with a depth rating of $6000 \mathrm{~m}$. It consists of a sequence of chains, steel wires, floatation devices and polyamide (PA) ropes. The breaking strength is $\sim 12$ tons near the surface. At the deeper mooring parts, the dynamic forces due to the buoy movement are damped, thus relaxing the breaking strength to $\sim 4$ tons down to the anchor. The uppermost section of the mooring is made from PVC-mantled steel wire to protect the mooring from fish biting. A short chain of $10 \mathrm{~m}$ in the upper part is included to additionally damp the buoy's behaviour. The whole mooring is deployed with a scope of 1.05 , while the PA rope has an additional $10 \%$ elongation. Floatation modules are included to allow easy recovery as well as in case of mooring failures - a buoyancy of all recoverable

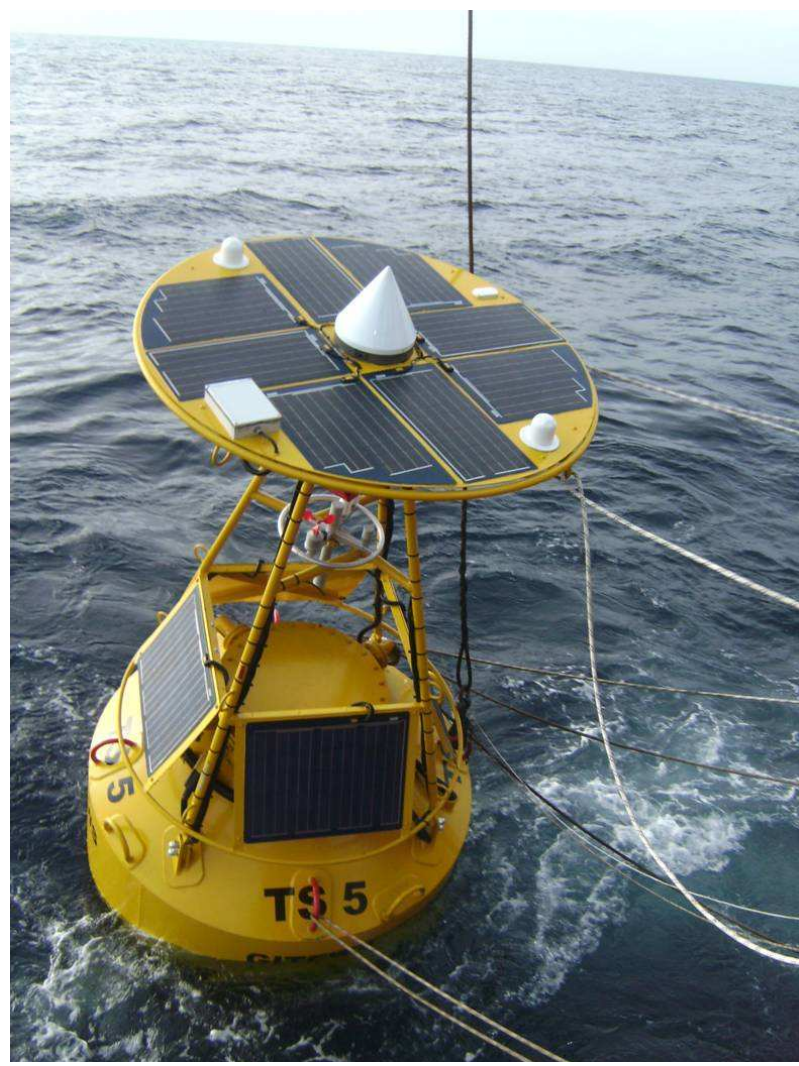

Fig. 2b. GITEWS buoy TS5 during deployment operation. On the top ring the GPS antenna (middle) is surrounded by the different communication antennas (BGAN, Iridium, PASTI). The meteorological sensor arm is mounted inside the tower. Solar panels provide power for uninterrupted operation.

parts. Swivels on both ends of the mooring are decoupling possible rotations of the buoy. An acoustic release unit is added for recovering the buoy and most parts of the mooring system. The anchor consists of a forerunner PA rope, a chain and the anchoring weight of $\sim 3$ tons. Floating modules above the releaser prevent it from colliding with the anchoring weight or the ocean bottom. To avoid any drag of the whole mooring, a Brittany anchor is connected to the anchoring weight.

Under calm weather conditions, the forces between the buoy and the mooring system are minimized. At the same time, the allowed offset angle between the buoy and the anchor weight (sway radius) guarantees a stable underwater communication, meeting the requirements of the transducer used in the bottom unit of the OBU or PACT system (Boebel et al., 2010). Increasing forces, e.g., due to severe weather conditions, cause an increased swaying, but this does not effect the quality of the underwater communication. An example of a typical mooring configuration is given in Fig. 3 . 


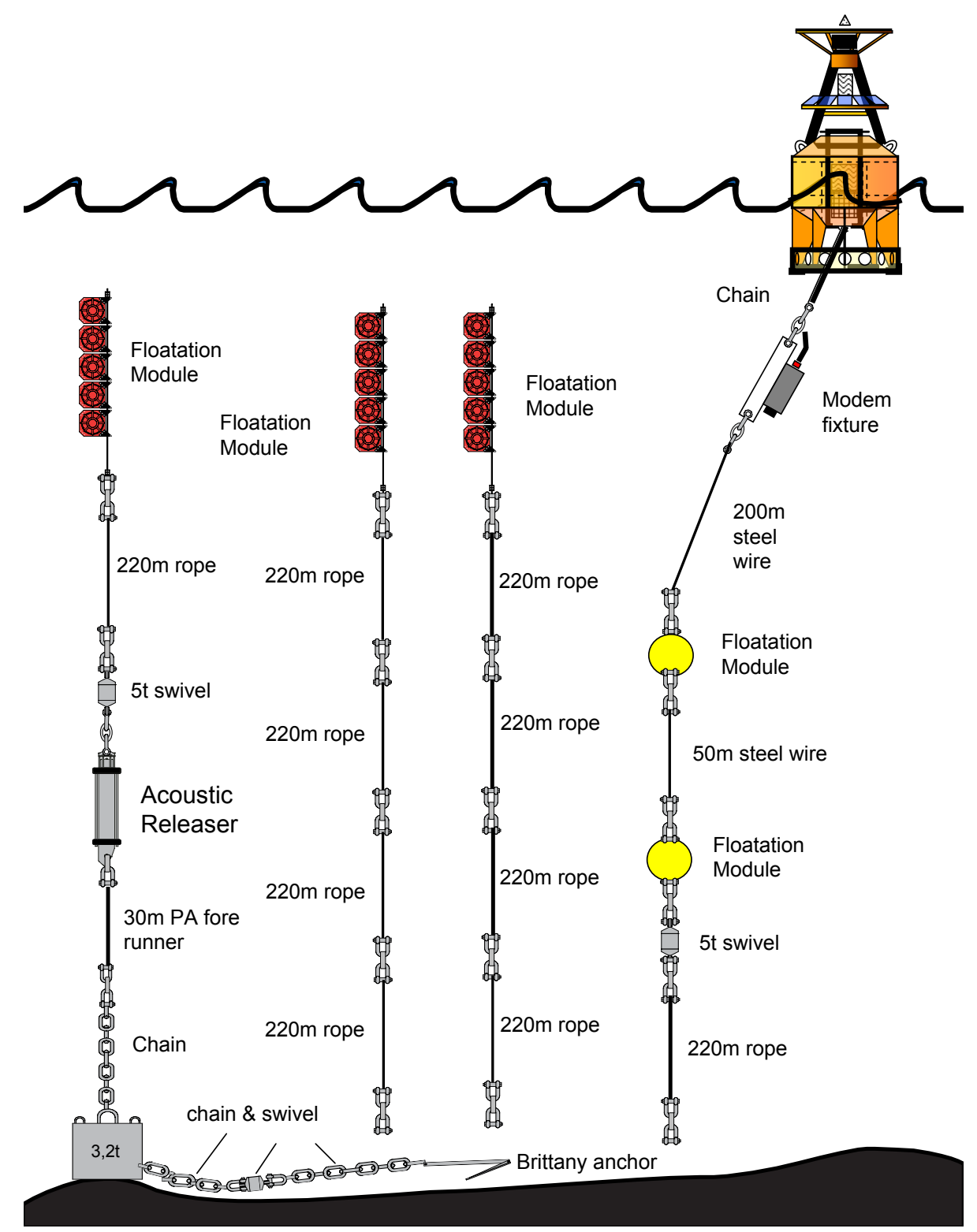

Fig. 3. Typical mooring configuration for $2500 \mathrm{~m}$ water depth for a buoy hosting an acoustic modem. All equipment (except the buoy) is rated and tested for water pressure of up to a $6000 \mathrm{~m}$ water column. The mooring was designed by Nautilus GmbH, Bremen (Germany).

\subsection{Instrumentation}

The main parts of a GITEWS buoy are the embedded PC104 computer, batteries, charge controllers, a battery manager, GPS, a tilt sensor and dipping sensors. Three batteries with a total capacity of 765Ah provide the necessary power buffer. The Linux-operated PC104, combined with the battery manager, is operating and managing the attached instrumentation, such as GPS or an underwater acoustic modem, using dedicated software modules. The integrated 4-GB flash disc has the capacity to store data for several months.
The system includes a high-quality low-power GNSS PolaRx3 receiver from Septentrio NV (Netherlands) (http:// www.septentrio.com). It allows tracking of GPS, GLONASS and the future GALILEO signals. To limit the data volume for transmission, only GPS signals are tracked. To correct the GPS measurements for the tilting of the buoy, a tilt sensor is installed inside. For tsunami warning purposes, a lowcost tilt sensor is installed, while for precise applications (e.g., ground truthing of satellite measurements) a fiber optic gyro may be added. In the earlier versions of the GITEWS buoys, a GEMAC (IS2A60P20 $\pm 60^{\circ}$ ) tilt sensor (http:// www.gemac-chemnitz.de) and a Crossbow VG700CA fiber 
optic gyro (http://www.xbow.com) were operated in parallel for comparison. The latter was removed while the GEMAC tilt sensor remained. It is installed as near as possible to the vertical inner axis of the buoy.

Three DKP7000 absolute pressure sensors (Driesen+Kern $\mathrm{GmbH}$, Germany, http://www.driesen-kern.de) are mounted to the underwater part of the buoy which allows accounting for the dipping, while the buoy moves with the sea state. The dipping values are pressure-compensated by using the meteorological sensor mounted at the buoy.

GITEWS buoys may serve for multi-hazard warning systems as well as for weather monitoring. A meteorological component is added to the buoy, monitoring air pressure and temperature, wind speed, gust and humidity. In addition, the water temperature and salinity is measured to correct the dipping values for changes in the water density.

\subsection{Communication and data transfer}

For off-shore installations, satellite communication is the only possible way to timely transmit data. Meteorological buoys use low-bit rate communication devices like, e.g., Iridium (http://www.nalresearch.com) or the GTS system (EUMETSAT, 2009). The bandwidth of these communication lines is sufficient for e.g., ocean bottom pressure data, but not for GPS or ocean bottom seismometer data. Therefore, the GITEWS buoys are equipped with a multitude of communication devices. The main communication line is Inmarsats broad band global area network (BGAN) system (Inmarsat Global Limited, 2009). BGAN is a superior compromise between power consumption, bandwidth and communication cost. Originally, the BGAN was designed for static field applications that require antenna pointing. However, the NERA1010 BGAN (http://www.thrane.com) has an antenna with an aperture of $60^{\circ}$ half-width. In equatorial and near-equatorial regions, this is sufficient to establish a reliable data transmission. In the current setup, it allows data transfer rates from 2 to $10 \mathrm{kbps}$, with average values of more than $7 \mathrm{kbps}$. The BGAN is operated on a hot-standby basis except the data connection, which is self-terminating between the transmission time slots. For outgoing traffic, the data line can be re-established within a few seconds. For incoming traffic a remote activation by SMS from the Tsunami Warning Center in Jakarta is necessary if the unit is in an idle mode. This activation procedure takes usually less than two minutes. BGAN technology allows transmission of significant amounts of GPS and, e.g., ocean bottom seismometer data for warning purposes.

As an alternative for the BGAN communication an IRIDIUM modem (SCGS Modem, A3LA-DGS) is integrated. Although the bandwidth of $3 \mathrm{kbps}$ is not sufficient to transfer large volumes of data, it was tested successfully to transmit highly compressed raw GPS data. Additionally, two PASTI modems, based on the geostationary satellite-based data transmission service, are used as a backup system. This $2.4 \mathrm{kbps}$ data service is provided by Inmarsat, based on satellite infrastructure and modems of the Indonesian ACeS system provider (http://www.acesinternational.com).

\subsection{Operational concept}

The buoys GPS system and auxiliary sensors are working continuously. All data is stored for later retrieval. In normalmode operation, the buoy transmits status information and some low-bit rate data every few hours. Due to the high sampling rate and the resulting amount of GPS data, it is not regularly transmitted. In case of a tsunami, there are two options to initiate GPS data transmission from the buoy to the warning center. If the buoy is equipped with an active OBU or PACT system (Boebel et al., 2010), it can be internally triggered into a tsunami reporting mode. The buoy is then transmitting the pre-defined GPS data set including a backlog of data. In case of a GPS-only buoy or if the buoy was not triggered by the OBU/PACT system, the warning center is able to activate the buoy remotely. The buoy continues data transmission every two minutes until the alarm is cancelled by the Tsunami Warning Center in Jakarta.

Today, GPS technology is able to provide kinematic height information with reasonable accuracy. Recently, a few attempts have been made to estimate the instantaneous sea surface height by processing the GPS data from buoys with the precise point positioning technique (PPP) (e.g., Colombo, 2004; Chen et al., 2004; Geng et al., 2010). However, a realtime network and a GPS real-time processing infrastructure would be necessary to provide updated orbit and clock products in-time when PPP is used in tsunami warning systems.

For GITEWS, GPS data of one or more reference stations on land is used to estimate sea surface heights from the GPS buoys. To complement the existing GPS network in Indonesia and to increase the number of possible GPS reference stations, several continuously operated high-rate GPS stations have been installed (e.g., Schöne et al., 2011) in addition to several real-time stations of the International GNSS Service (IGS) network in this area (Dow et al., 2009).

\section{Data analysis and results}

Using the GITEWS GPS buoys for tsunami detection requires a near real-time data transfer to a warning center and an efficient processing. Handling GPS data is separated into two parts. The first part is the pre-processing of the raw data stream directly at the buoy; the second part is the processing of the GPS and the sea level data at the Tsunami Warning Center in Jakarta.

In Fig. 4, the general data flow is outlined. The GPS data is sampled with $1 \mathrm{~Hz}$, while the dipping values are acquired every $0.1 \mathrm{~Hz}$ and the tilt values are continuously sampled from the analog tilt sensor. By using the tilt, dipping, and 


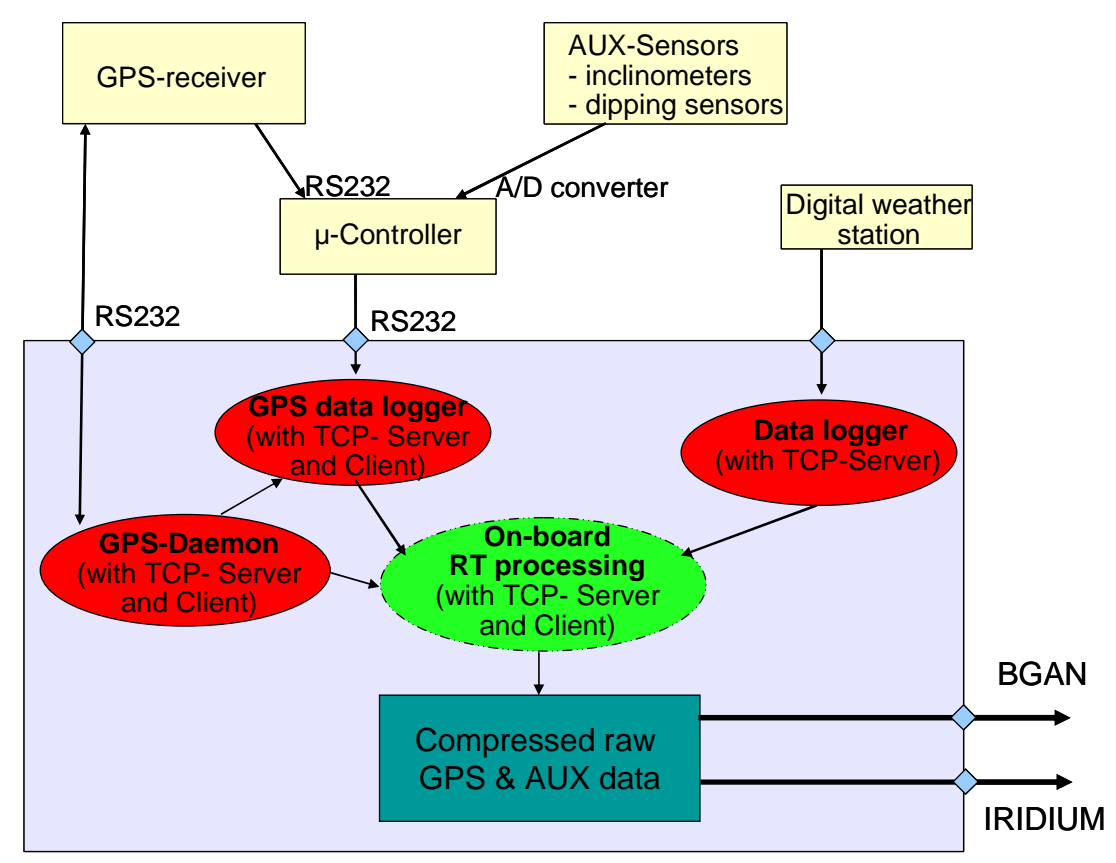

Fig. 4. GPS and auxiliary data flow at the GITEWS buoy. The data streams from the GPS receiver; air pressure, tilt, and dipping sensors are combined directly onboard the buoy creating a compact data format.

air pressure data, a correction value is computed to reduce the GPS antenna height to the instantaneous sea surface. All tilt and dipping values, as well as the height correction value, are attached to the GPS data stream by a $\mu$-Controller. To decrease the amount of data for transmission, the resulting data stream is split. The full $1 \mathrm{~Hz}$ data including all raw auxiliary data is stored for scientific use at the buoy. For the transmission to the Tsunami Warning Center in Jakarta, the data stream is down-sampled. All quantities in the RINEX data (Gurtner and Estey, 2007) which are not necessary for the GPS processing are discarded, so only a minimal set of GPS data and correction values for reducing the antenna height to the sea surface are retained. After compression, the data volume has sufficiently decreased for satellite data transmission.

The second part of the data handling is performed at the Tsunami Warning Center in Jakarta. All incoming data are separated into auxiliary data and GPS data. The GPS data is processed by Bernese Software (Dach et al., 2007). As soon as new GPS data has been transmitted to the Warning Center in Jakarta, the processing is repeated on the newly arrived data. To limit the computing time, a maximum of three hours of GPS data is processed. The result is a time series of height values for the buoy's GPS antenna reference point. In a consecutive step, the auxiliary height correction data and the GPS processing results are merged to procure instantaneous sea surface heights (iSSH).

The time series of the iSSH is a mixture of the sea state, tidal signals and the possible tsunami signal. All three types of signals are separated in the frequency domain. Periods of wind-generated waves vary up to $20 \mathrm{~s}$, while astronomical tidal signals in the open ocean have wave periods from about $12 \mathrm{~h}$ and more. Typical periods of tsunami waves range from $10 \mathrm{~min}$ to one hour. A Butterworth low-pass filter suppresses the wind waves by removing signals with wave periods of less than two minutes. For de-tiding and estimation of the tsunami arrival time at the location of the buoy, the sea level event detection algorithm (SLE) (Schöne et al., 2011; Pérez et al., 2009) is applied. The resulting time series including the estimated onset time of a possible tsunami is transmitted via the tsunami service bus (Fleischer et al., 2010) for further use at the Tsunami Warning Center in Jakarta.

\subsection{Examples}

\subsubsection{Data analysis of buoy TS07A (Sumatra 2)}

The processing for this study was done with TRACK software, part of GAMIT/GLOBK (Herring et al., 2009). TRACK uses the Melbourne-Wellenhoff Wide Lane technique to resolve L1-L2 and then a combination of techniques to determine L1 and L2 cycles separately. Bias fixing is done by a floating point analysis. To obtain the best estimates of the station position, a smoothing filter handles especially unresolved bias parameters.

GPS data for a period of 18 days (day 64 till 81, 2010) was processed for the buoy TS07A $\left(0^{\circ} 34^{\prime} \mathrm{S}, 97^{\circ} 23^{\prime} \mathrm{E}\right.$, Northern Sumatra) (Figs. 1 and 5). As a reference, the GPS-controlled tide gauge station (Schöne et al., 2011) at Telukdalam (Nias/Indonesia) with a baseline length of about $140 \mathrm{~km}$ was 


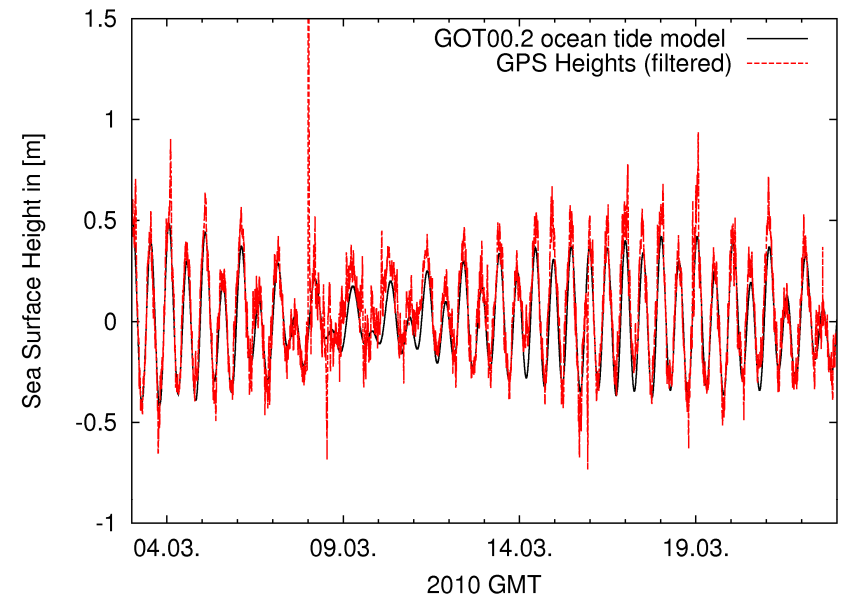

Fig. 5. Comparison of GPS data and the ocean tide model GOT00.2 (Ray, 1999) for a GITEWS off-shore buoy. The model is shown in green; the GPS time series is shown in red. Differences in phase and amplitude are due to the model. Spikes in the GPS curve occur commonly through undetected cycle slips in the reference base station.

used. For both, Telukdalam and the GPS buoy, $1 \mathrm{~Hz}$ data is available. To analyse the long-term behaviour of the derived sea level time series, the data is filtered by a Butterworth lowpass filter with a cutoff of $2 \mathrm{~min}$ as described above. This filter suppresses sea state effects in the time series but also reveals some outliers. These outliers are due to undetected or unresolved cycle slips or data gaps.

No measured in-situ reference data, e.g., ocean bottom pressure data, is available this particular time period. Thus, a comparison with the GOT00.2 global ocean tide model (an improved model of GOT99; Ray, 1999) is carried out. The difference between the GPS-derived time series and the GOT00.2 tidal model shows small phase shifts and amplitude differences. Both effects are addressed to the tidal model (see e.g., Savcenko and Bosch, 2008). To allow an estimation of the quality of the results, the sea level time series was analysed by a harmonic analysis using a least square approach (Foreman, 1977). The resulting main partial constituents were used for a prediction of the respective tidal heights. For the estimation of the RMS of the differences, the time series and predictions have been reduced equidistantly from $1 \mathrm{~Hz}$ to $1 \mathrm{~min}$ data. A basic outlier removal for differences between the tidal model and the GPS heights was applied for values larger $0.5 \mathrm{~m}$, reducing the data set by $0.5 \%$ of the data. The resulting RMS for the time series of 18 days is $\sim 9 \mathrm{~cm}$ and shows close agreement with the estimated tidal model.

To gain a more statistically-supported background on the quality and reliability of the GPS-derived sea level time series, it is also interesting to analyse the data intervals typical for a tsunami alert sequence (tsunami mode). In such an alerting sequence, a minimum of $30 \mathrm{~min}$ of data is

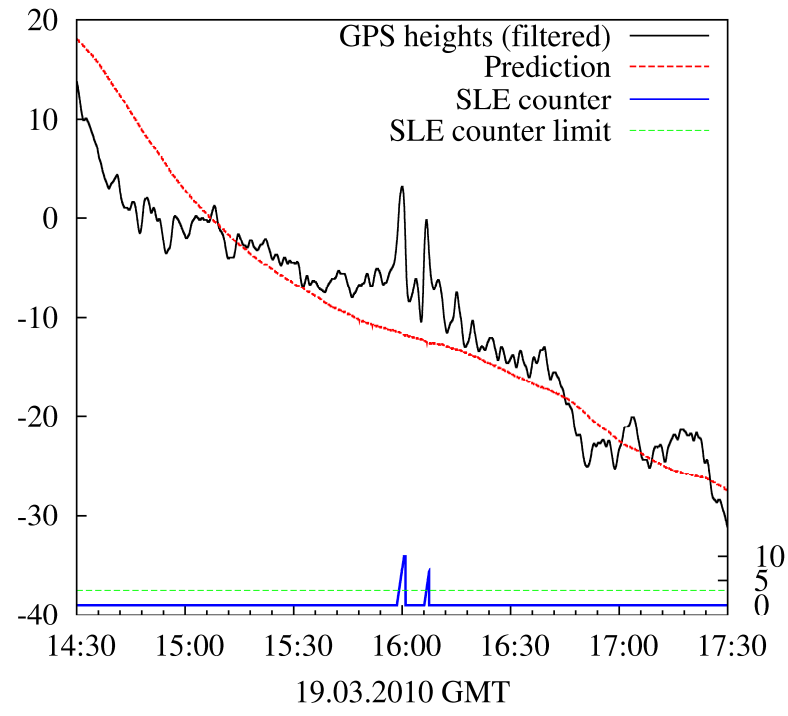

Fig. 6. GPS-derived sea level time series (in $\mathrm{cm}$ ) of a typical tsunami alert sequence in GITEWS ( $\sim 3 \mathrm{~h}$ length). The prediction (red) is based on the SLE algorithm (see Sect. 5 in Pérez et al., 2009). The difference to the model is in the range of $5 \mathrm{~cm}$. Under normal conditions, tsunamis with amplitudes of $10 \mathrm{~cm}$ can be detected. The graph shows the GPS-derived sea level time series (black) and the prediction (red) in $\mathrm{cm}$ (left hand side axis). The right hand side axis is the SLE trigger (value between 1 and 10) (blue) and the SLE counter limit (here 3 ) for tsunami alerting (green).

provided prior to the earthquake source time and the buoy is operated in tsunami mode for up to $2 \mathrm{~h}$. Thus, in the following, a time series of 3 hours for day 78 (19 March 2010) is analysed. Figure 6 shows the predicted sea level curve from the SLE detection algorithm (red curve, see Sect. 5 in Pérez et al., 2009) and a typical sea level curve (black line) measured by the buoy. Wind-induced waves with wave periods less then 2 min have again been removed by the Butterworth filter. Two outliners were detected by the SLE algorithm (blue curve), which can have various reasons but most likely result from insufficiencies in the GPS processing. Except for the outliers, the comparison between the predicted and measured sea level curve shows differences of up to $5 \mathrm{~cm}$ for wave periods also typical for tsunamis $(10 \mathrm{~min}$ and above). This leads to the conclusion that a tsunami should have at least $10 \mathrm{~cm}$ in amplitude to be detectable by GPS buoys.

As a further test, the standard deviation of the differences between the estimated tidal model and the GPS time series is analysed in a sliding window for periods of one hour. For the processed data set, about $68 \%$ of the standard deviations are smaller than $5 \mathrm{~cm}$, and about $95 \%$ are smaller than $10 \mathrm{~cm}$. This also supports the conclusion that tsunamis can be detected if they exceed the amplitude of $10 \mathrm{~cm}$. With this accuracy, data from GPS buoys contain invaluable information during a tsunamogenic earthquake. 


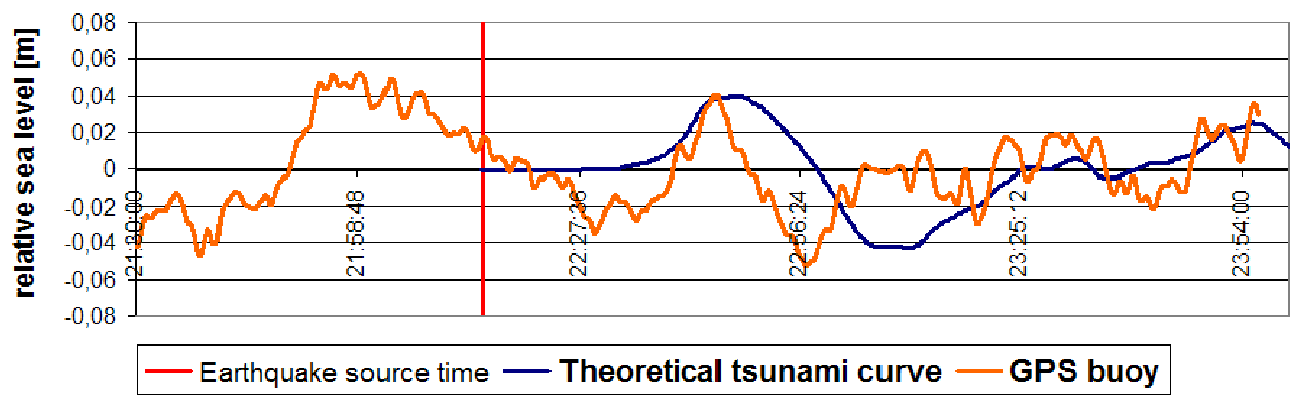

Fig. 7. Sea level curve acquired during the M7.6 earthquake on 6 April 2010 off Banda Aceh (Indonesia). The corrected and de-trended GPS derived sea level curve (orange) and a theoretical tsunami curve (blue) based on a forward modelling (A. Babeyko, GFZ Potsdam, personal communication, 2010) are shown.

\subsubsection{Tsunami on 6 April 2010, Northern Sumatra}

Another example of GPS derived sea level heights was acquired during the M7.6 earthquake on 6 April 2010 (GFZ, $2010^{2}$ ) and is shown in Fig. 7. The modelling of the tsunami propagation from the earthquake source model (A. Babeyko, GFZ Potsdam, personal communication, 2010) suggests a small tsunami wave of $4 \mathrm{~cm}$ deviation from normal at the position of a GITEWS buoy. The GPS processing was done by using the same setup as for the examples described above. The reference station for the GPS processing is again Telukdalam (Nias/Indonesia). The processed time series shows some minor variations with deviations of $5 \mathrm{~cm}$ prior to the earthquake source time. For the time of the expected event, the sea level curve coincides with the theoretical tsunami curve. The peak is 2 min earlier than the prediction; the decay is more rapid but shows similarity with the $-4 \mathrm{~cm}$ decay from the tsunami propagation model. For the next hour, both curves agree within the limit of the accuracy of the GPS technology. Considering the difficulties also of the numerical tsunami propagation modelling, the agreement between the two curves is excellent.

This data set shows the current limitation of the detection of small tsunamis with GPS buoys. On one hand, the derived sea level curves are sometimes noisy and difficult to interpret. On the other, overlaying the GPS-derived sea level curves with the information from a tsunami propagation model does assist the decision process and increase the reliability of a tsunami verification or falsification.

\section{Conclusions}

The GPS buoys developed in GITEWS proove the suitability of using GPS technology in tsunami warning systems. Especially in Indonesia and with extremely short warning times, GPS-derived offshore sea level time series provide correct tsunami arrival times and amplitudes and thus benefit the reliability of the whole tsunami warning system. The results presented in Sect. 3 show that the current detection threshold for GITEWS GPS buoys is between $5 \mathrm{~cm}$ (for $68 \%$ of the time) and $10 \mathrm{~cm}$ (for $95 \%$ of the time) tsunami wave heights. For the off-shore Indonesian area towards the Indian Ocean, destructive tsunamis may have initial heights of several decimeters at the source area. The expected amplitudes are thus much larger than the GPS buoy detection threshold. With new technological developments in real-time networks and processing, this situation should be quickly improving in the near future.

Acknowledgements. The authors thank their colleagues at the GFZ and BPPT for their help in installing, maintaining, and operating the buoys. Especially the captains, officers and crews of RV SONNE (Germany), Baruna Jaya III and Baruna Jaya IV have contributed with their help and their knowledge of sea technology to further the success of this project.

We also wish to thank Tom Herring (MIT) and Simon McClusky (MIT) for their help with the GAMIT/TRACK software.

For assistance in developing the GITEWS buoy system we thank Thees Behrens (Behrens Schiffs- und Schweißtechnik $\mathrm{GmbH}$, Hamburg), Gerald Abich (Nautilus GmbH \& RF Bremen, Germany), Walter Grauerholz and Frank Heise (Centrosolar AG, Hamburg). The design phase of the GITEWS tsunami buoys was kindly supported by A. Berger (Altefähr, Water and Shipping Office Stralsund, Germany).

We also thank the two anonymous reviewers for their helpful comments and suggestions.

This work has been carried out under the German Ministry of Research and Education grant 03TSU01.

This is publication 107 of the GITEWS project (German Indonesian Tsunami Early Warning System).

Edited by: J. Lauterjung

Reviewed by: two anonymous referees

\footnotetext{
${ }^{2}$ http://geofon.gfz-potsdam.de/db/eqpage.php?id=gfz2010gtdx
} 


\section{References}

Boebel, O., Busack, M., Flueh, E. R., Gouretski, V., Rohr, H., Macrander, A., Krabbenhoeft, A., Motz, M., and Radtke, T.: The GITEWS ocean bottom sensor packages, Nat. Hazards Earth Syst. Sci., 10, 1759-1780, doi:10.5194/nhess-10-17592010, 2010.

Bonnefond, P., Exertier, P., Laurain, O., Pierron, F., and Jan, G.: Absolute calibration of Topex/Poseidon, Jason-1 and Jason-2 altimeters in Corsica, OSTST 2009 meeting, Seattle, USA, available at: http://www.aviso.oceanobs.com/fileadmin/ documents/OSTST/2009/oral/Bonnefond_et_al.pdf, 2009.

Born, G. H., Parke, M. E., Axelrad, P., Gold, K. L., Johnson, J., Key, K. W., Kubitscheck, D. G., and Christensen, E. J.: Calibration of the TOPEX altimeter using a GPS buoy, J. Geophys. Res., 99(C12), 24517-24526, 1994.

Chen, W., Hu, C. W., and Li, Z. H.: Kinematic GPS precise point positioning for sea level monitoring with GPS buoy, Journal of Global Positioning Systems, 3(1-2), 302-307, 2004.

Colombo, O. L., Sutter, A. W., and Evans, A. G.: Evaluation of Precise, Kinematic GPS Point Positioning, in: Proceedings of the 17th International Technical Meeting of the Satellite Division of The Institute of Navigation (ION GNSS 2004), Long Beach, California, 21-24 September 2004, 1423-1430, available at: http://www.ion.org/search/view_abstract.cfm?jp=p $\backslash$ \&idno $=5821,2004$.

Dach, R., Hugentobler, U., Fridez, P., and Meindl, M.: Bernese GPS Software Version 5.0, Astronomical Institute, University of Bern, 2007.

Dow, J. M., Neilan, R. E., and Rizos, C.: The International GNSS Service in a changing landscape of Global Navigation Satellite Systems, J. Geodesy, 83, 191-198, doi:10.1007/s00190-0080300-3, 2009.

EUMETSAT: TD 16 - Meteosat Data Collection and Retransmission Service, http://www.eumetsat.int/idcplg? IdcService=GET_FILE $\backslash \&$ dDocName=PDF_TD16_MSG_CRS $\backslash$ \&RevisionSelectionMethod=LatestReleased, 2009.

Fleischer, J., Häner, R., Herrnkind, S., Kloth, A., Kriegel, U., Schwarting, H., and Wächter, J.: An integration platform for heterogeneous sensor systems in GITEWS - Tsunami Service Bus, Nat. Hazards Earth Syst. Sci., 10, 1239-1252, doi:10.5194/nhess-10-1239-2010, 2010.

Foreman, M. G. G.: Manual for tidal heights analysis and prediction, Institute of Ocean Sciences, Patricia Bay, Pacific Marine Science Rep. 77-10, 66 pp., 1977.

Geng, J., Teferle, F. N., Meng, X., and Dodson, A. H.: Kinematic precise point positioning at remote marine platforms, GPS Solution, 14(4), 343-350, doi:10.1007/s 10291-009-0157-9, 2010.

Gurtner, W. and Estey, L.: RINEX - The Receiver Independent Exchange Format, Version 3.00, University of Berne, Switzerland, 2007.

Hein, G. W., Landau, H., and Blomenhofer, H.: Determination of Instantaneous Sea Surface, Wave Heights, and Ocean Currents Using Satellite Observations of the Global Positioning System, Mar. Geod., 14, 217-224, 1990.
Herring, T. A., King, R. W., and McClusky, S. C.: Documentation for the GAMIT/GLOBK GPS processing software release 10.3, Mass. Inst. of Technol., Cambridge, USA, http://www-gpsg.mit. edu/ $\sim$ simon/gtgk/docs.htm, 2009.

Inmarsat Global Limited: http://www.inmarsat.com/Downloads/ English/BGAN/Collateral/bgan_overview_brochure_EN.pdf? language $=\mathrm{EN} \backslash$ \& textonly=False, 2009.

Pérez, B., Vela, J., Woodworth, P. L., Wijeratne, E. M. S., Tinti, S., Bressan, L., Schöne. T., and Illigner, J.: Software for Automatic Detection, Analysis and Quality Control of highfrequency and low-latency sea level signals, EU TRANSFER project, Deliverable 4.3.4, Project no. 037058 (GOCE), available at: www.transferproject.eu, 2009.

Ray, R. D.: A global ocean tide model from Topex/Poseidon altimetry: GOT99, NASA Tech. Memo 209478, Goddard Space Flight Center, 55 pp., 1999.

Rudloff, A., Lauterjung, J., Münch, U., and Tinti, S.: Preface "The GITEWS Project (German-Indonesian Tsunami Early Warning System)", Nat. Hazards Earth Syst. Sci., 9, 1381-1382, doi:10.5194/nhess-9-1381-2009, 2009.

Savcenko, R. and Bosch, W.: EOT08a - empirical ocean tide model from multi-mission satellite altimetry, DGFI, München, Report No. 81, available at: www.dgfi.badw.de, 2008.

Schöne, T., Reigber, C., and Braun, A.: GPS Offshore Buoys and Continuous GPS Control of Tide Gauges, Int. Hydrogr. Rev. (New Series), 4(3), 64-70, 2003.

Schöne, T., Illigner, J., Manurung, P., Subarya, C., Khafid, Zech, C., and Galas, R.: GPS-controlled tide gauges in Indonesia - a German contribution to Indonesia's Tsunami Early Warning System, Nat. Hazards Earth Syst. Sci., 11, 731-740, doi:10.5194/nhess-11-731-2011, 2011.

Teruyuki, K., Yukihiro, T., Masao, K., Hideshi, K., Hiroshi, I., Masakatsu, M., Akira, Y., and Takayuki, T.: Real-time observation of tsunami by RTK-GPS, Earth Planets Space, 52, 841-845, 2000.

Teruyuki, K., Yukihiro, T., Toshihiko, N., and Shun'ichi, K.: Development of a GPS buoy system for monitoring tsunami, sea waves, ocean bottom crustal deformation and atmospheric water vapour, Geophysical Research Abstracts (GRA), Vol. 12, EGU2010-7377, EGU General Assembly, 2010.

Toshihiko, N., Teruyuki, K., Nobuo, M., Hiroaki, I., Yukihiro, T., and Masao, M.: Offshore Tsunami Monitoring Network Design Using GPS Buoys and Coastal On-site Sensors, Coast. Eng., 1529-1540, 2006.

Watson, C. S., White, N. J., Coleman, R., Church, J. A., Morgan, P. J., and Govind, R.: TOPEX/Poseidon and Jason-1: Absolute calibration in Bass Strait, Australia, Mar. Geod., 27(1-2), 107131, doi:10.1080/01490410490465373, 2004.

Watson, C. S., Coleman, R., and Handsworth, R.: Coastal tide gauge calibration: a case study at Macquarie Island using GPS buoy techniques, J. Coastal Res., 24(4), 1071-1079, 2008. 